\title{
Role of PET in the evaluation and understanding of coronary physiology
}

\author{
Thomas H. Schindler, MD, ${ }^{\mathrm{a}, \mathrm{b}}$ Xiao-Li Zhang, MD, PhD, ${ }^{\mathrm{b}}$ Gabriella Vincenti, $M D{ }^{\mathrm{a}}$ \\ Leila Mhiri, MD, ${ }^{a}$ René Lerch, MD, ${ }^{a}$ and Heinrich R. Schelbert, MD, PhD ${ }^{b}$
}

\section{INTRODUCTION}

Positron emission tomography (PET) combined with tracer kinetic modeling ${ }^{1-5}$ affords the assessment of regional myocardial blood flow (MBF) in milliliters per gram per minute, thus extending the scope of conventional scintigraphic imaging in the noninvasive identification and characterization of coronary circulatory function or dysfunction in early subclinical stages of coronary artery disease (CAD) ${ }^{2,6}$ Experimental and clinical investigations indicate the importance of the functional integrity of coronary circulatory function to mediate antiatherosclerotic and antithrombotic effects. ${ }^{70}$ Vice versa, an impairment of coronary circulatory function reflects a proatherosclerotic state with substantial diagnostic and prognostic implications. ${ }^{9-14}$ The noninvasive identification and characterization of coronary circulatory function or dysfunction by means of PET offer important insight into the complex nature of the mechanisms underlying functional alterations of the coronary circulation and, thus, may contribute to unraveling the pathophysiology of the early development of the coronary atherosclerotic process. For example, by evaluating MBF responses to sympathetic stimulation with cold pressor testing (CPT) or hyperemic MBF increases during pharmacologic vasodilation, as well as their responses to pharmaceutical intervention ${ }^{15,16}$ or their relation to markers of systemic inflammation, insulin resistance, or adipocytokines, ${ }^{17-21}$ PET measurements of MBF may contribute to a better understanding of the development of the early stages of the CAD process. Conceptually, the results of such investigations with PET

From the Nuclear Cardiology, Cardiovascular Center, University Hospital of Geneva, Geneva, Switzerland, a and Department of Molecular and Medical Pharmacology, David Geffen School of Medicine at UCLA, Los Angeles, Calif. ${ }^{\text {. }}$

This work was supported in part by grant HL 33177 from the National Heart, Lung, and Blood Institute, Bethesda, Md.

Reprint requests: Thomas H. Schindler, MD, Cardiologie Nucléaire, Service Cardiologie, Département de Médecine Interne, Hôpitaux Universitaires de Genève, Rue Micheli-du-Crest 24, 1211 Genève 14, Switzerland; thomas.schindler@hcuge.ch.

J Nucl Cardiol 2007;14:589-603.

$1071-3581 / \$ 32.00$

Copyright $@ 2007$ by the American Society of Nuclear Cardiology. doi:10.1016/j.nuclcard.2007.05.006 quantification of MBF could also provide substantial information to develop specific medical therapy strategies to prevent the initiation or development of CAD in coronary risk patients.

\section{INVASIVE ASSESSMENT OF CORONARY VASOMOTOR FUNCTION}

The investigation of coronary vasomotor (circulatory) function is usually confined to patients with chest pain syndromes undergoing coronary angiography. The determination of alterations in epicardial diameter in response to intracoronary infusion of acetylcholine, bradykinin, or substance $\mathrm{P}$ is obtained by computer-based measurements of the coronary diameter (quantitative coronary angiography $[\mathrm{QCA}])^{22,23}$ Endothelium-dependent vasodilators such as acetylcholine specifically stimulate the receptor-mediated release of endothelium-derived nitric oxide (NO) that induces the epicardial artery to dilate through relaxation of the vascular smooth muscle cells. Epicardial vasodilation in response to specific acetylcholine stimulation therefore defines normal endothelial function. In the presence of dysfunctional endothelium of the epicardial artery, however, the concurrent smooth muscle cell constrictor effects of acetylcholine overcome the endothelium-mediated vasodilation, ${ }^{23}$ and a lack of vasodilation or, more commonly, paradoxical vasoconstriction ensues. ${ }^{23,24}$ Another attractive and more physiologic approach to the assessment of epicardial endothelial function is to determine flow-mediated and, thus, also endothelium-related epicardial vasodilation by QCA during hyperemic flow increases resulting from pharmacologic vasodilation with adenosine or papaverine. ${ }^{23,25,26}$ Whereas flow-mediated epicardial vasodilation defines normal endothelial function, an impairment or absence of flow-mediated epicardial vasodilation is indicative of a dysfunctional vascular endothelium. In addition, substances such as nitroglycerin or sodium nitroprusside supply NO directly to the vascular smooth muscle cell layer that induces epicardial vasodilation, independent of the functional state of the vascular endothelium.

The assessment of coronary blood flow to evaluate the responses of the coronary microcirculatory system requires 
an intracoronary Doppler catheter and the placement of a flow wire. ${ }^{23}$ Notably, endothelium-dependent vasodilators such as acetylcholine also increase coronary blood flow, mirroring their concomitant vasodilator effects on the coronary arteriolar resistance vessels. Increases in coronary flows to acetylcholine stimulation as measured with the Doppler flow wire therefore reflect normal endotheliumdependent coronary arteriolar vasomotor function, whereas an impairment or absence of coronary flow is appreciated as endothelial dysfunction of the arteriolar vessels. Conversely, substances such as papaverine or adenosine exert a vascular smooth muscle cell-relaxing effect at the site of the coronary resistance (arteriolar) vessels and, consequently, induce predominantly endothelium-independent coronary flow increases. ${ }^{2,22,23}$

\section{PET MEASUREMENTS OF MBF}

Approaches that apply PET to determine regional MBF in milliliters per gram per minute entail intravenous administration of positron-emitting tracers of MBF such as nitrogen 13 ammonia, oxygen 15labeled water, and more recently, rubidium 82 and imaging of the radiotracer's transit time through the central circulatory system and its extraction and retention in the myocardium. ${ }^{1,3-5,27-29}$ The final static 15minute frame of the serially acquired image data sets is reoriented into short- and long-axis myocardial slices and, as in our approach, assembled into polar maps. ${ }^{18,19}$ Regions of interest (ROIs) are assigned automatically by the analysis software program to the territories of the 3 major coronary arteries, and a $25-\mathrm{mm}^{2} \mathrm{ROI}$ is assigned to the left ventricular blood pool. The ROIs are then copied to all serially acquired image data sets after they have been resliced and assembled into polar maps via the same reorientation parameters, as applied to the final 15-minute static image. Thereafter the arterial tracer input function and the tracer uptake into the myocardium are determined. ${ }^{1,3}$ The resulting time-activity curves from these ROIs are then fitted with tracer compartment models, which describe the exchange of radiotracer between tissue compartments and the volume of tracer distribution in each compartment, and regional MBFs are calculated in milliliters per gram per minute. ${ }^{1-4,6,30}$ Tracer kinetic models correct for the physical decay of the radioisotope, for spillover of activity between the left ventricular blood pool and the myocardium, ${ }^{31}$ and for partial-volume effect, assuming a uniform myocardial wall thickness of $1 \mathrm{~cm} .{ }^{32} \mathrm{~N}-13$ ammonia and O-15labeled water have been widely validated against independent microsphere blood flow measurements in animals and yield reproducible values of MBF. ${ }^{1,4}$ Similarly, measurements of MBF with N-13 ammonia and O-15labeled water in humans yield comparable estimates of
$\mathrm{MBF}^{27,33}$ More recently, Rb-82 has emerged as a promising and reliable flow tracer ${ }^{30}$ but still needs to be validated further. The short physical half-lives of these positron-emitting tracers (9.8 minutes for $\mathrm{N}-13$ ammonia and 2.4 minutes for O-15-labeled water compared with only 78 seconds for $\mathrm{Rb}-82$ ) allow serial evaluations of MBF in one study session.

\section{DETERMINANTS OF MBF AND FLOW RESERVE}

The concept of the coronary flow reserve that describes the vasodilatory capacity of the coronary circulation to increase coronary flows to 3 to 5 times from baseline in response to increased metabolic demand was first described by Coffman and Gregg. ${ }^{34}$ Subsequently, Mosher et $\mathrm{a}^{35}$ added the concept of coronary autoregulation that provided a more physiologic framework for the coronary flow reserve. There are a number of determinants of resting MBF, whereas the oxygen demand, as a function of heart rate, blood pressures, myocardial contractility, and ventricular preload, is the prevalent factor in the modulation of resting MBF. When the metabolic myocardial oxygen demand is constant, MBF within the range of its autoregulation is widely independent of the coronary perfusion pressure. It follows, therefore, that within this range of coronary autoregulation-so-called plateau-coronary flow changes little despite alterations in perfusion pressures. ${ }^{36}$ Conversely, during maximal or submaximal vasodilation of the coronary arteriolar resistance vessels during pharmacologic vasodilation, the coronary flow does not underlie any more the autoregulation and changes linearly with the intracoronary perfusion pressure. In this concept, the ratio of hyperemic to resting coronary flow defines the coronary flow reserve.

With regard to coronary flow reserve, it is worthy to note that it does not necessarily reflect the true vasodilator capacity of the coronary circulation. Coronary flow reserve can decline as a result of an increase in resting flow, a decrease in maximum hyperemic flow, or both. Factors that increase myocardial oxygen demand, such as arterial hypertension, increased myocardial contractility, increased left ventricular wall stress, and tachycardia, induce an increase in resting flow. On the other side, maximum hyperemic coronary flow may decline in the presence of a focal flow-limiting epicardial lesion, in the presence of microvascular disease in patients with hypertension or diabetes, or as a consequence of increases in extravascular resistive forces paralleled by increases in left ventricular pressures in patients with congestive heart failure or hypertension. Despite these limitations of the concept of the coronary flow reserve, it is a useful index by which to determine the functional significance or downstream effects of focal epicardial artery lesions 
and the functional improvement after coronary revascularization and for the evaluation of coronary circulatory function in individuals with subclinical or clinically manifest CAD. ${ }^{2,37,38}$

\section{RESTING MBF}

PET-measured MBF at rest in healthy volunteers has been reported to range between 0.4 and 1.2 $\mathrm{mL} \cdot \mathrm{g}^{-1} \cdot \min ^{-1} \cdot{ }^{36,39-43}$ The variability in these individual resting MBFs was most likely related to differences in left ventricular myocardial workload at the time of assessment, whereas methodologic factors may have contributed to this. ${ }^{44}$ There is a close linear correlation between resting $\mathrm{MBF}$ and the rate-pressure product (defined as the product of systolic blood pressure and heart rate) as an index of cardiac work and, thus, also metabolic oxygen demand. ${ }^{36,40,45}$ The continuous agerelated increase in resting $\mathrm{MBF}$ has also been attributed to increases in cardiac work as a result of alterations predominantly in systolic blood pressure. ${ }^{36}$ More controversial are the MBF values at rest between men and women. Some investigations observed higher values of resting $\mathrm{MBF}$ in women than in men, ${ }^{40,43,46}$ which was suggested to be most likely related to sex-related differences in the lipid profile, whereas others did not find such a difference. ${ }^{36}$

\section{PET IN NONINVASIVE ASSESSMENT OF CORONARY CIRCULATORY DYSFUNCTION}

Approaches to assess coronary circulatory function implicate measurements of MBF with PET at rest and its responses to physiologically or pharmacologically induced coronary flow increases, including bicycle exercise, dobutamine stress, sympathetic stimulation with CPT, vascular smooth muscle cell relaxation at the site of

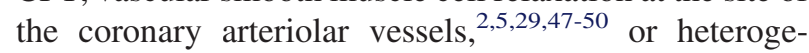
neous responses of $\mathrm{MBF}$ in more apical and more basal regions of the left ventricle as a possible noninvasive index of epicardial vasomotion. ${ }^{51,52}$

\section{SYMPATHETIC STIMULATION WITH CPT}

Noninvasive measurements of MBF with PET at rest and its response to sympathetic stimulation by CPT have been appreciated to entail specific information on endothelium-related coronary vasomotor function. ${ }^{15,49,53-56}$ Immersion of the left hand into ice water causes a sympathetically mediated increase in heart rate and blood pressures and, thus, an increase in myocardial workload. This increase in myocardial oxygen demand, as reflected by the elevation in myocardial workload, is associated with vasodilation of the coronary arteriolar resistance vessels through the release of presumably adenosine as a metabolic vasodilator. ${ }^{57} \mathrm{As}$ a decrease in coronary vascular resistance ensues, an increase in coronary inflow is observed, which in turn leads to a flow-mediated and, thus, endotheliumdependent dilation of the upstream coronary vessel segment. Consequently, an increase in cardiac work is normally paralleled by commensurate flow-mediated coronary vasodilation (Figure 1) and an increase in MBF as measured with PET. ${ }^{15,17,43,49}$ In the presence of a functional abnormality of endothelium-related coronary vasomotion, however, the coronary flow increases during sympathetic stimulation do not mediate a flowrelated vasodilation. As a consequence, the vasoconstrictor effects of the sympathetically mediated stimulation of the vascular smooth muscle cells prevail and are not overcome by a normal flow-related coronary vasodilation (Figure 2). 6,23,49 The MBFs during CPT are then attenuated, absent, or even paradoxical, which denotes an impairment of endothelium-dependent coronary vasomotor function. . $^{15,17,49,56,58}$

Several studies assessing coronary vasomotor function support the validity and value of noninvasive PET measurements of changes in $\mathrm{MBF}$ during CPT from rest as an index of endothelium-dependent coronary vasomotion. For example, coronary flow increases during CPT, as assessed invasively with Doppler wire during coronary angiography, have been shown to closely correlate with the flow response to acetylcholine stimulation (Figure 3). ${ }^{23,53}$ Coronary flows during sympathetic stimulation with CPT, therefore, may indeed probe endotheliumrelated vasomotor function and, thereby, the functional integrity of the vascular wall. ${ }^{23,49}$ Notably, a similar association was also observed between the epicardial vasomotor response to CPT and acetylcholine stimulation, suggesting that the epicardial vasomotor response to CPT is intimately related to the integrity of endothelial function. ${ }^{23,58}$ Further CPT-induced changes in epicardial luminal diameter, as determined by QCA, and PETmeasured responses of MBF to CPT were closely correlated. ${ }^{15,17,49}$ More direct evidence for the involvement of the endothelium in the CPT-mediated MBF responses has been provided by Campisi et al. ${ }^{56}$ In chronic smokers presenting with impairment of MBF responses to CPT, intravenous infusion of L-arginine as a substrate of nitric oxide synthase (NOS) restored the MBF increase to CPT, most likely as a result of increases in the bioavailability of endothelium-derived NO.

There are also investigations with PET determining $\mathrm{MBF}$ and, at the same time, regional adrenergic neuronal function by use of 11-labeled hydroxyephedrine. These comparative investigations by PET could demonstrate the involvement of adrenergic neurons in the modulation of MBF responses to CPT. For example, the uptake of 11-labeled hydroxyephedrine in cardiac adrenergic nerve 
A

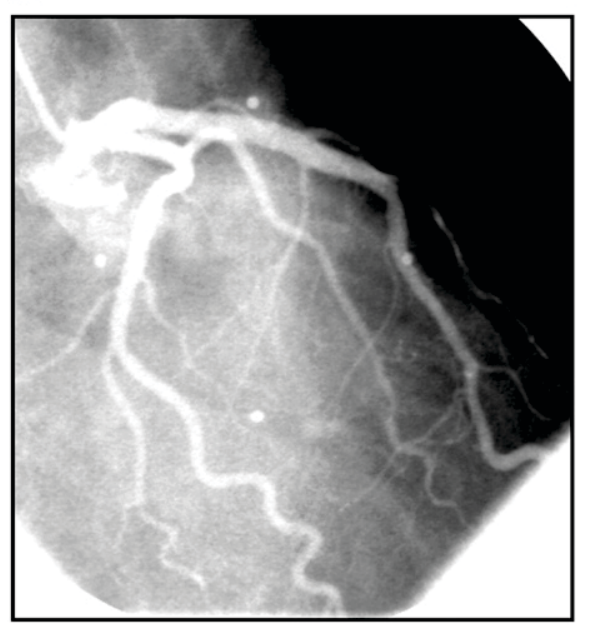

C

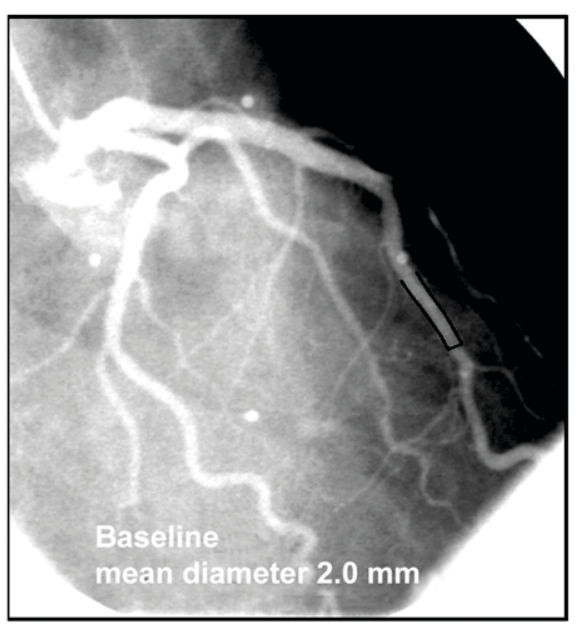

B

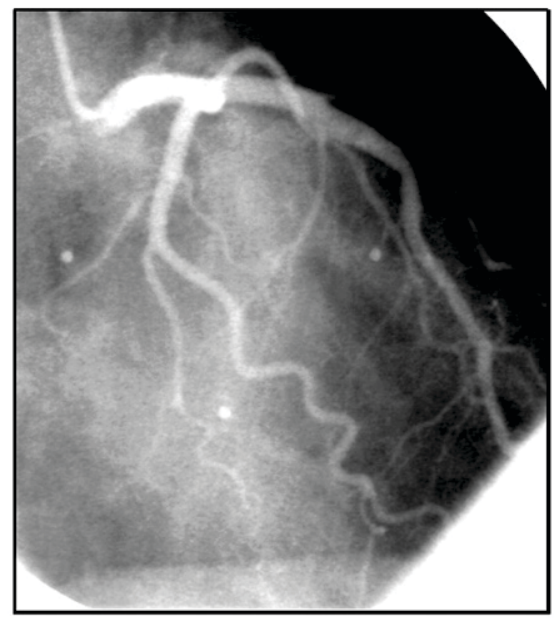

D

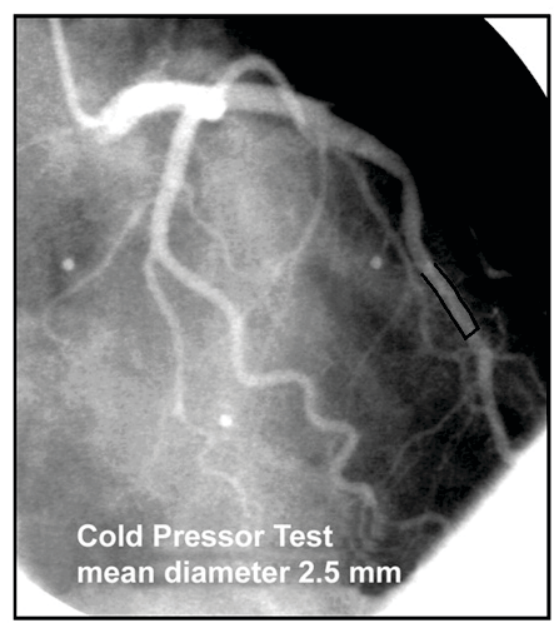

Figure 1. A, Normal coronary angiogram of left coronary tree in right anterior oblique view of a healthy individual without coronary risk factors. B, Corresponding angiogram during sympathetic stimulation with CPT. C and D, Quantitative angiographic assessment of proximal-mid left anterior descending artery segment at rest (mean diameter, $2.0 \mathrm{~mm})(\mathbf{C})$ and during CPT (mean diameter, 2.5 $\mathrm{mm})(\mathbf{D})$. (Reprinted with permission from reference. ${ }^{49}$ )

terminals is diminished in patients with cardiac allografts with a neuronal state of denervation or in diabetic patients with neuropathy and, thus, neuronal dysfunction. $^{59-63}$ In these populations studied, reductions in myocardial carbon-11-labeled hydroxyephedrine retention were paralleled by a reduced MBF response to CPT. In particular, in diabetic patients MBF responses to sympathetic activation with CPT were somehow still preserved in myocardial regions with normal C-11labeled hydroxyephedrine. ${ }^{62}$ These findings indeed suggest that both sympathetic activation and flow-mediated vasomotor function modulate the MBF increases during stimulation with CPT.

\section{HYPEREMIC MBFS DURING PHARMACOLOGIC VASODILATION}

Another interesting and more clinically used approach is the assessment of coronary circulatory function by pharmacologically induced hyperemic MBF increases. ${ }^{2,5,44,64,65}$ Vascular smooth muscle-relaxing substances such as dipyridamole, adenosine, or more recently, adenosine triphosphate or adenosine receptor agonists ${ }^{66}$ decrease the resistance to flow at the site of the coronary arteriolar resistance vessels and, thereby, induce a maximal or submaximal hyperemic flow increase. Because these substances induce hyperemic flow in- 
A

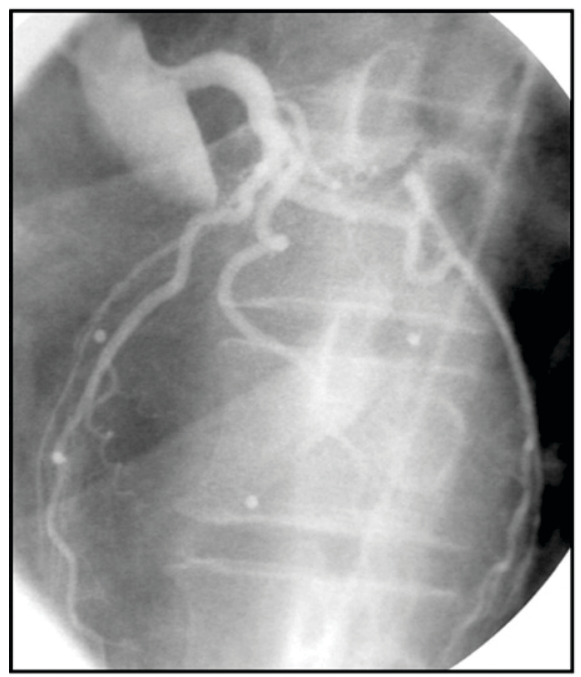

C

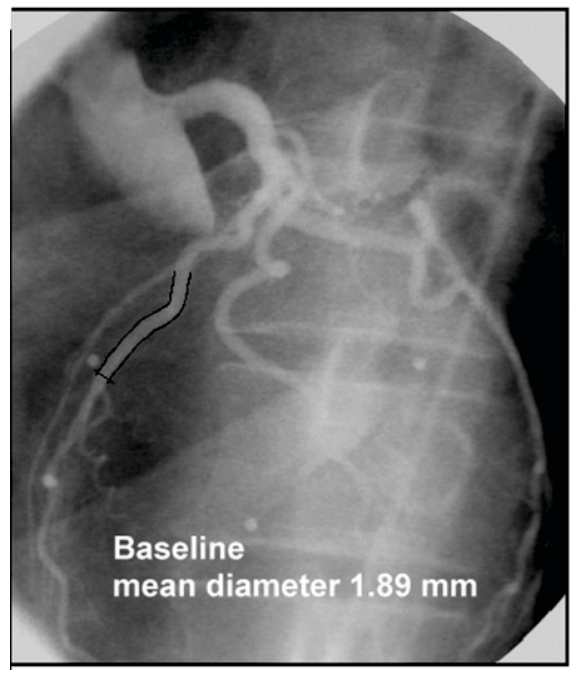

B

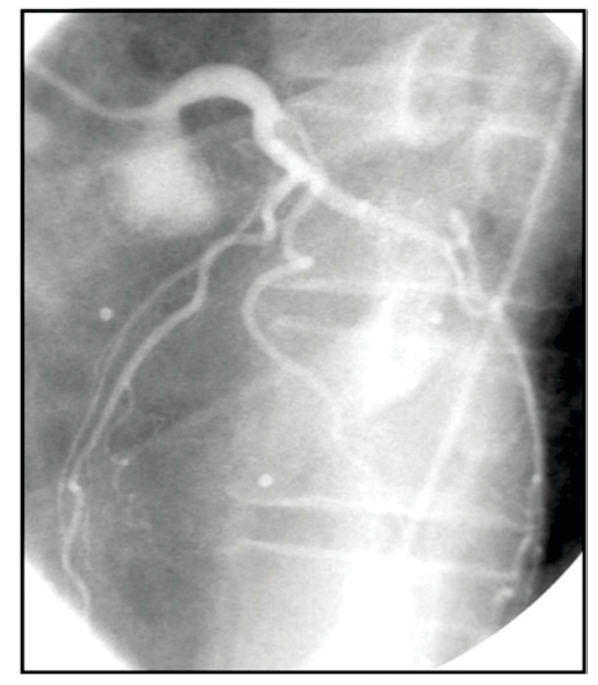

D

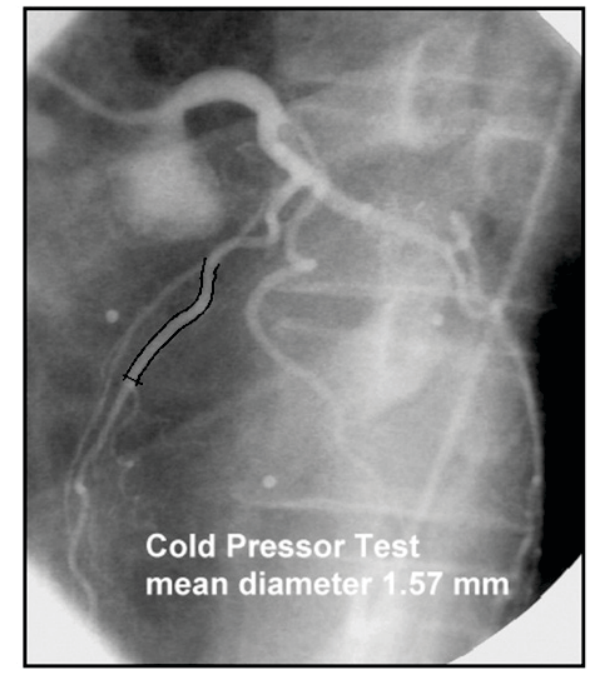

Figure 2. A, Normal coronary angiogram of left coronary artery tree in left anterior oblique view in a chronic smoker at rest. B, Corresponding coronary angiogram during CPT. C and D, Quantitative angiographic assessment of proximal-mid left anterior descending artery segment at rest (mean diameter, $1.89 \mathrm{~mm})(\mathbf{C})$ and during CPT (mean diameter, $1.57 \mathrm{~mm})(\mathbf{D})$. (Reprinted with permission from reference. $\left.{ }^{49}\right)$

creases through vascular smooth muscle cell relaxation, the resulting hyperemic coronary flow increase is deemed to be a measure of a predominantly endotheliumindependent flow response. Inhibition of the endothelial nitric oxide synthase (eNOS) by intravenous infusion of $N^{\mathrm{G}}$-monomethyl-L-arginine significantly reduces adenosine-induced MBF increases by $20 \%$ to $25 \%$ as measured with PET (Figure 4). ${ }^{67,68}$ Thus shear-sensitive components of the coronary endothelium contribute in part through flow-mediated coronary vasodilation to the overall hyperemic MBF increases during pharmacologic vasodilation, ${ }^{23,67,68}$ which may also be seen as total integrated coronary circulatory function.

\section{HETEROGENEITY IN LONGITUDINAL, BASE-TO-APEX MBF}

A heterogeneity in longitudinal myocardial perfusion or MBFs has been described first during hyperemic coronary flow increases owing to pharmacologic vasodilation in patients with diffuse $\mathrm{CAD}^{69}$ and, subsequently, with quantitative MBF measurements in individuals with 


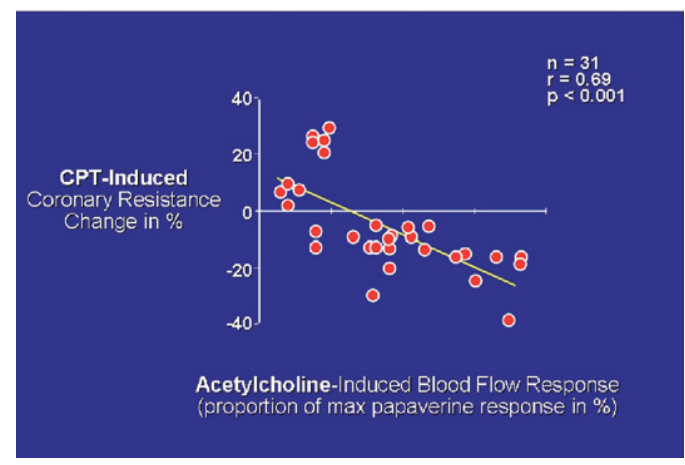

Figure 3. Association between coronary flow response to CPT and acetylcholine stimulation during coronary angiography in 12 normal control patients and in 19 patients with diffuse CAD. The CPT-induced changes in coronary vascular resistance inversely and significantly correlated with the extent of endothelial dysfunction of the coronary arteriolar vessels as determined with acetylcholine stimulation. (Reprinted with permission from reference. ${ }^{53}$ )

coronary risk factors. ${ }^{51,52}$ Fluid dynamic consequences of CAD-related vessel stiffness or functional abnormalities of the epicardial conduit vessels may account for the longitudinal heterogeneity in myocardial perfusion. On the basis of the Hagen-Poiseuille equation, ${ }^{70-72}$ intracoronary resistance relates to the velocity of the blood flow and inversely to the fourth power of the vessel diameter. Normal functioning of the coronary vascular endothelium guarantees that increases in flow velocity during exercise or pharmacologic vasodilation are associated with a flow-mediated dilation of the coronary circulation that balances the velocity-induced increase in coronary resistance so that the resistance is kept low. ${ }^{73,74}$ An abnormal structural or functional coronary vascular state during the early development of CAD, however, is commonly associated with an impairment of flowmediated epicardial vasodilation. Under such conditions, the resistance to higher coronary flow increases leads to a progressive proximal-to-distal decline in intracoronary pressure along the epicardial artery, ${ }^{70}$ which is assumed to be a cause for a gradual, base-toapex relative decline or heterogeneity in myocardial perfusion or MBF. ${ }^{51,52,69,70}$ The assessment of a heterogeneity in longitudinal myocardial perfusion or quantitatively in MBFs by means of PET, therefore, could be a promising noninvasive index of early structural or functional alterations of the CAD process predominantly at the site of the epicardial artery.

\section{REPRODUCIBILITY OF MBFS DURING VASOMOTOR STRESS}

As PET-measured MBF responses to cold exposure or to pharmacologic vasodilation are increasingly ap-

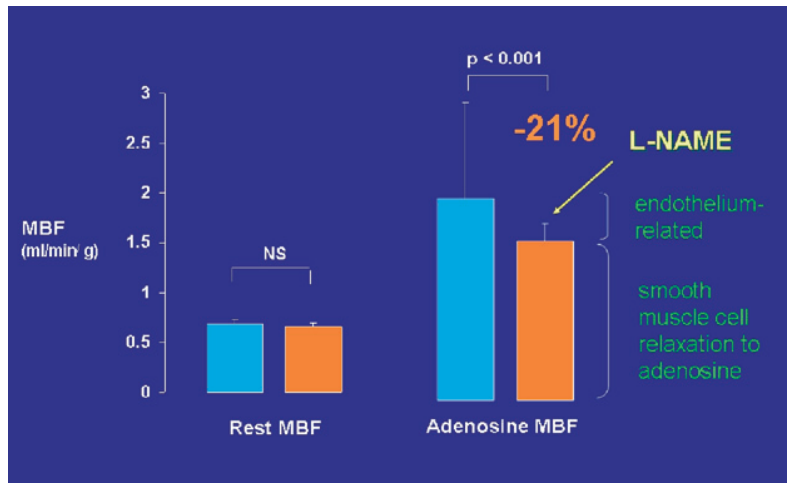

Figure 4. Hyperemic MBF increase after adenosine stimulation and its alteration with the intravenous infusion of the NO synthase inhibitor $N^{\mathrm{G}}$-nitro-L-arginine methyl ester $(L-N A M E)$ (4 mg per kilogram of body weight). In the presence of L-NAME, the hyperemic MBF response was attenuated by $21 \%$, which is likely to reflect the impairment of the flowmediated and, thus, endothelium-derived and NO-mediated vasodilation by L-NAME. NS, Not significant. (Data from reference. ${ }^{67}$ )

plied to determine the effects of lifestyle modifications or therapeutic interventions on coronary circulatory function, ${ }^{15,16,20,48,75-78}$ there is a need to establish the reproducibility of these MBF measurements. Such an analysis is necessary to assess the true measurement error of PET-measured MBFs in repeat assessments or to determine the sample size of future study populations needed for serial clinical PET studies. Previous studies have demonstrated that hyperemic MBF increases during pharmacologic vasodilation can be measured reproducibly with N-13 ammonia or O-15-labeled water and PET. ${ }^{64,79}$ As recent investigations demonstrate, there is also a reliable 1-day reproducibility for CPT-related MBF when determined with O-15-labeled water. ${ }^{80}$ More recently and in a more extended investigation, ${ }^{81}$ the hemodynamic and MBF responses to CPT, as measured with N-13 ammonia and PET, were demonstrated to be highly reproducible in the short term as well as in the long term (1-day and 2- to 3-week protocol) (Table 1). ${ }^{81}$ The range of measurement errors, as denoted by the standard error of estimate (SEE) for the endotheliumrelated change in MBF $(\triangle \mathrm{MBF})$ from rest to $\mathrm{CPT}$, was $0.09 \mathrm{~mL} \cdot \mathrm{g}^{-1} \cdot \mathrm{min}^{-1}$ for short-term and 0.17 $\mathrm{mL} \cdot \mathrm{g}^{-1} \cdot \min ^{-1}$ for long-term repeat measurements. It follows, therefore, that alterations in $\triangle \mathrm{MBF}$ in serial pharmaceutical studies that are above this range of SEE values are indeed likely to be related to beneficial effects of pharmaceutical interventions on coronary endothelial function. ${ }^{81}$ The data from the latter study also provided useful information with regard to the sample size needed to sufficiently power a study for serial MBF studies with CPT. Accordingly, a sample size of about 22 individuals 
Table 1. MBF and hemodynamics at measurements $1(M 1)$ and $2(M 2)$ on the same day, and measurement 3 (M 3) after 2 weeks, for all study participants $(n=20)$

\section{Mean difference}

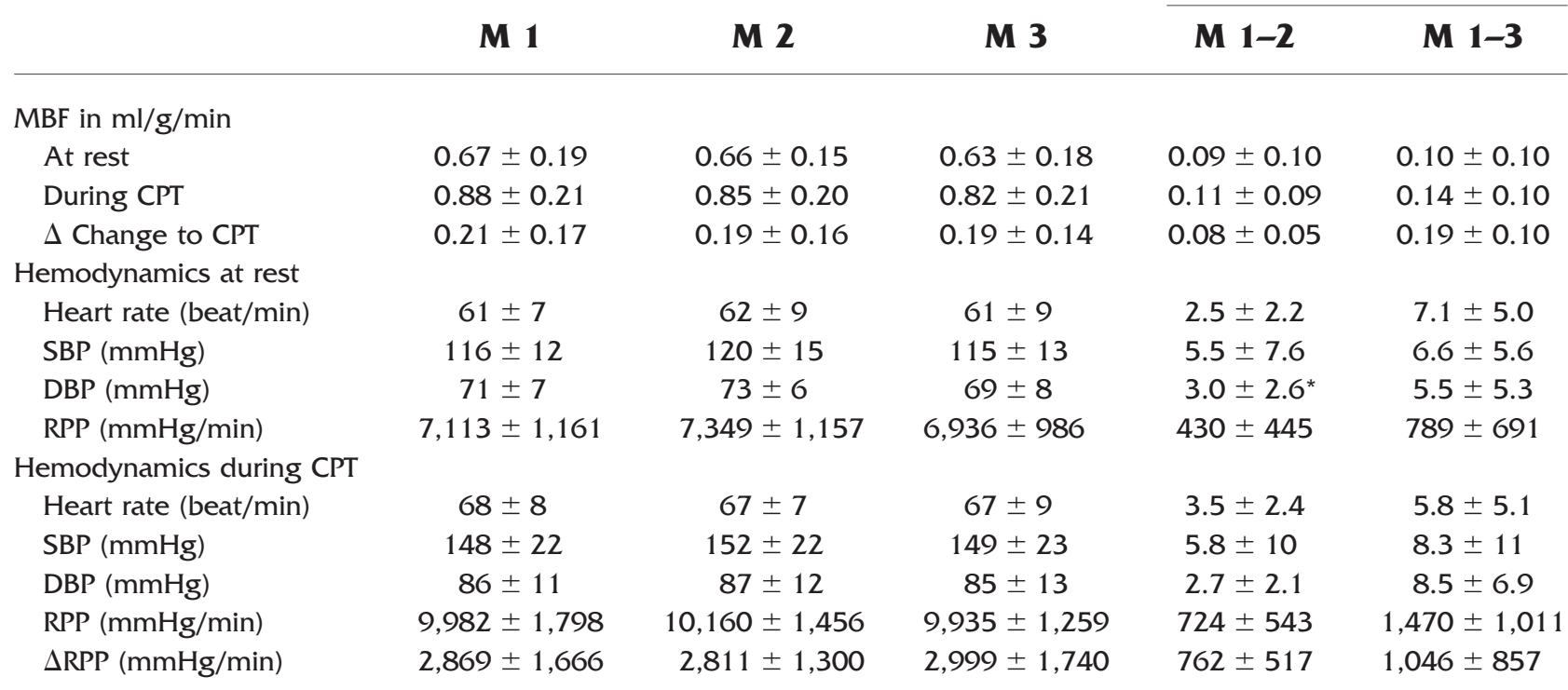

SBP, Systolic blood pressure; DBP, diastolic blood pressure; RPP, rate-pressure product.

(With kind permission from reference 81 ).

${ }^{*} P \leq 0.05$ for difference by paired $t$-test.

Table 2. MBF repeatability coefficient in different studies

\begin{tabular}{|c|c|c|c|c|c|c|c|}
\hline & $\begin{array}{l}\text { Schindler } \\
\text { et al. }\end{array}$ & & $\begin{array}{l}\text { Siegrist } \\
\text { et al. }{ }^{80}\end{array}$ & $\begin{array}{l}\text { Kaufmann } \\
\text { et al. }\end{array}$ & $\begin{array}{l}\text { Wyss } \\
\text { et al. }{ }^{47}\end{array}$ & $\begin{array}{l}\text { Jagathesan } \\
\text { et al. }{ }^{83}\end{array}$ & \\
\hline Radiotracer & $\mathrm{N}-13$ ammonia & & O-15 water & ${ }^{15} \mathrm{O}$-water & ${ }^{15} \mathrm{O}$-water & ${ }^{15} \mathrm{O}$-water & \\
\hline Period & ST ( 1 day) & LT (2 wk) & ST (1 day) & ST (1 day) & ST (1 day) & LT (24 wk) & \\
\hline MBF at baseline & 0.26 & 0.26 & NA & 0.17 & 0.26 & $0.30^{*}$ & $0.26^{+}$ \\
\hline MBF during CPT & 0.28 & 0.31 & 0.41 & NA & NA & NA & NA \\
\hline$\triangle \mathrm{MBF}$ to $\mathrm{CPT}$ & 0.18 & 0.27 & NA & NA & NA & NA & NA \\
\hline $\begin{array}{l}\text { MBF during } \\
\text { adenosine }\end{array}$ & NA & NA & NA & 0.94 & 1.34 & NA & NA \\
\hline $\begin{array}{l}\text { MBF during bicycle } \\
\text { exercise }\end{array}$ & NA & NA & NA & NA & 0.82 & NA & NA \\
\hline $\begin{array}{l}\text { MBF during } \\
\text { dobutamine }\end{array}$ & NA & NA & NA & NA & NA & 0.49 & 0.58 \\
\hline
\end{tabular}

ST, Short term; $L T$, long term; NA, not assessed.

(With kind permission from reference 81).

*Ischemic myocardium.

${ }^{\dagger}$ Remote myocardium.

with coronary risk factors is desirable for a long-term interventional pharmaceutical trial whereas a sample size of 14 would be sufficient for a 1-day protocol.

In interpreting the data of reproducibility studies, Bland and Altman ${ }^{82}$ proposed a repeatability coefficient (RPC) that is widely used to demonstrate the agreement between repeat measurements. The RPC can be used for a direct comparison of the precision of PET-determined MBFs between different studies (Table 2). With regard to the RPC for the endothelium-related $\triangle \mathrm{MBF}$ to $\mathrm{CPT}$, it was observed to be $0.18 \mathrm{~mL} \cdot \mathrm{g}^{-1} \cdot \mathrm{min}^{-1}$ for the short-term and $0.27 \mathrm{~mL} \cdot \mathrm{g}^{-1} \cdot \mathrm{min}^{-1}$ for the long-term reproducibility measurements with $\mathrm{N}-13$ ammonia and PET. ${ }^{81}$ Both values were found to be lower than the short-term RPC of 
CPT-related MBFs as measured with O-15-labeled water in a 1-day study protocol $^{80}$ and also for hyperemic MBF increases reported in previous studies, ${ }^{47,64,83}$ which have been reported to be between 0.49 and $1.34 \mathrm{~mL} \cdot \mathrm{g}^{-1} \cdot \mathrm{min}^{-1}$ (Table 2).

\section{CORONARY CIRCULATORY FUNCTION AND CARDIOVASCULAR EVENTS}

The causes of coronary circulatory dysfunction in patients with coronary risk factors are certainly multifactorial, whereas an increased vascular production of reactive oxygen species (ROS) derived from superoxide-producing endothelial enzymes, such as nicotinamide-adeninedinucleotide phosphate $(\mathrm{NAD}[\mathrm{P}] \mathrm{H})$ oxidase, xanthine oxidase, or uncoupled NO synthase, leading to a reduction in the bioavailability of endothelium-derived $\mathrm{NO}$, is thought to be a common final pathway underlying abnormal coronary circulatory function. ${ }^{84}$ An impairment of endotheliumdependent coronary circulatory function is commonly associated with other active processes such as inflammation, proliferation, or apoptosis, as well as the expression of vascular cellular adhesion molecules (eg, intercellular adhesion molecule). This so-called endothelial activation may reflect the initial injury of the vascular wall that may initiate and contribute to the development and progression of the atherosclerotic process. Such endothelial activation plays an important role in the pathogenesis of acute coronary syndromes, which is characterized by coronary plaque vulnerability; paradoxical vasoconstriction paralleled by endothelial dysfunction, which is likely to contribute to plaque rupture ${ }^{85,86}$; and increased thrombogenicity as a result of a loss of a potent antithrombotic endothelial surface. ${ }^{87} \mathrm{An}$ impairment of coronary circulatory function, therefore, is likely to reflect in part the vulnerability of a plaque to rupture, which may explain the independent predictive value of coronary circulatory dysfunction for future cardiovascular events..$^{9-11,88}$ It may be concluded that functional alterations of coronary circulatory function appear to reflect ongoing processes that modify the functional status of the arterial wall and may provide a rationale for the independent predictive value of functional abnormalities in coronary circulatory function for future cardiovascular events (Figure 5). ${ }^{10}$ Such functional alterations of the coronary circulation appear to be superior to the assessment of CADrelated structural alterations of the epicardial wall in the prediction of the future cardiovascular clinical outcome. ${ }^{89-93}$

\section{PET-DETERMINED CORONARY CIRCULATORY FUNCTION AND VASCULAR OXIDATION-REDUCTION STATE}

Measurements of MBF at rest and during various forms of vasomotor stress have contributed new in vivo

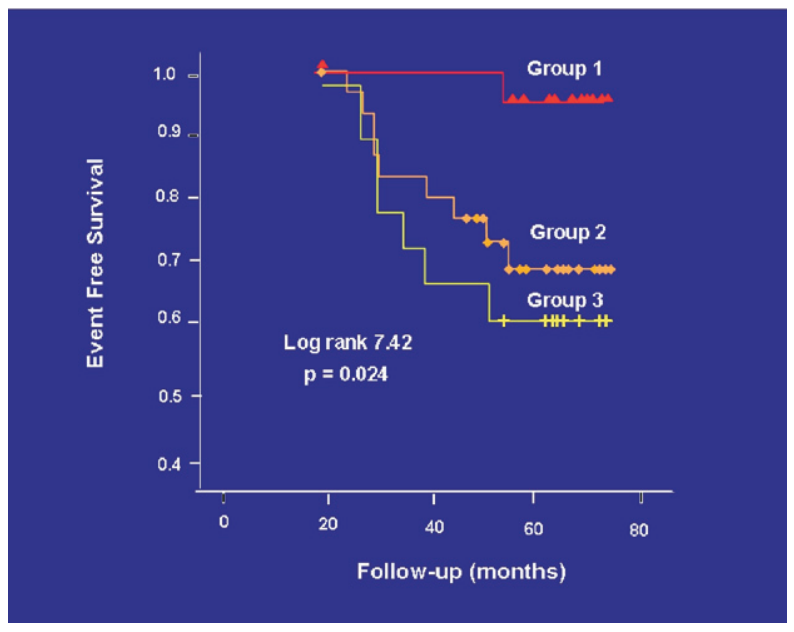

Figure 5. Prognostic value of PET-measured, endotheliumrelated MBF responses to sympathetic stimulation with CPT. The Kaplan-Meier analysis demonstrates an association between the incidence of cardiovascular events and the degree of the diminished $\mathrm{MBF}$ response to $\mathrm{CPT}(\triangle \mathrm{MBF} \geq 40 \%$ in group $1, \Delta \mathrm{MBF}<40 \%$ in group 2 , and $\Delta \mathrm{MBF} \leq 0 \%$ in group 3 ). (Reprinted with permission from reference. ${ }^{9}$ )

mechanistic insight into the mechanisms affecting coronary circulatory function in individuals with coronary risk factors. For example, Kaufmann et $\mathrm{al}^{77}$ showed that acute intravenous antioxidant intervention with vitamin $\mathrm{C}$, to reduce the oxidative stress burden in smokers, significantly increased hyperemic MBF increases to pharmacologic vasodilation. The latter findings strongly suggest ROS as a prevalent cause for the impairment of the total coronary vasodilator function in chronic smokers. In individuals with familial hypercholesterolemia or with secondary hypercholesterolemia, hyperemic MBFs during pharmacologic vasodilation are commonly reduced when compared with agematched control subjects. ${ }^{94-96}$ Notably, the hyperemic flow increases and myocardial flow reserve were inversely correlated with the severity of abnormal plasma lipid levels. Despite the well-known detrimental effects of total cholesterol plasma levels on the coronary circulation, it appears that not only total cholesterol but also low-density lipoprotein cholesterol is a major determinant of a reduced coronary vasodilatory capacity as determined with PET. ${ }^{94}$ Conversely, restoring tetrahydrobiopterin (BH4) deficiency in hypercholesterolemic individuals normalized adenosinestimulated hyperemic flow responses. ${ }^{76}$ Such a finding points out that $\mathrm{BH} 4$ deficiency may also contribute to coronary circulatory dysfunction, most likely through an uncoupling of endothelial $\operatorname{NOS}^{97}$ with further increases in ROS in hypercholesterolemia.

Of note, previous investigations using PET measurements of MBF at rest and the response to CPT demon- 


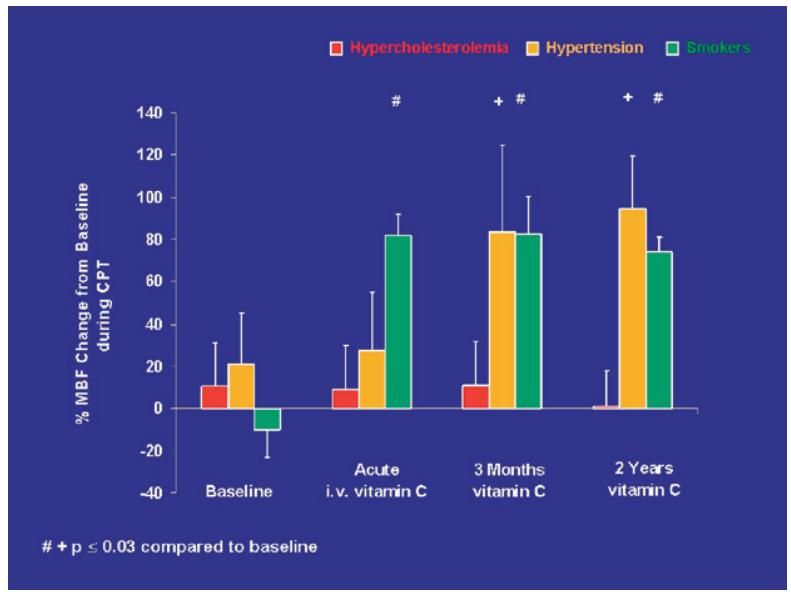

Figure 6. Effects of short-term and long-term antioxidant intervention on endothelium-related MBF responses to CPT. The graph demonstrates contrasting MBF responses to vitamin $\mathrm{C}$ challenges in hypercholesterolemic patients, smokers, and hypertensive patients. $i v$, Intravenous. (Reprinted with permission from reference. ${ }^{15}$ )

strated heterogeneous responses in endothelium-related MBFs during CPT to short- and long-term antioxidant intervention with vitamin $\mathrm{C}$ in patients with different coronary risk factors such as smoking, arterial hypertension, and hypercholesterolemia (Figure 6). ${ }^{15}$ Such in vivo findings by PET imaging ${ }^{15}$ may be in contrast to experimental investigations that proposed increases in ROS as the main common pathway underlying endothelial dysfunction ${ }^{84,98}$ and, thus, may suggest a rather complex mechanism that may account for abnormalities in coronary circulatory function. ${ }^{23}$ With regard to chronic smokers, short- and long-term antioxidant vitamin $\mathrm{C}$ challenges improved abnormalities in MBF responses to CPT, whereas no such beneficial effect was observed in individuals with hypercholesterolemia (Figure 6). This may suggest that abnormalities in endothelium-related coronary vasomotion in smokers are predominantly mediated by the release of ROS, whereas other mechanisms appear to prevail in the presence of hypercholesterolemia. For example, selective targeting of $\mathrm{G}$ protein-dependent signal transduction by oxidized low-density lipoprotein results in a diminished receptormediated stimulation of endothelial NO production. ${ }^{99}$ Interestingly, in hypertensive patients short-term vitamin $\mathrm{C}$ challenges did not lead to an improvement in impaired MBF responses to CPT. In contrast, after long-term application of vitamin $\mathrm{C}$ over a period of 3 months, a normalized endothelium-related MBF response to CPT was observed, which was also sustained after a 2-year follow-up. The reason for the delayed onset of the beneficial effect of vitamin $C$ challenges on endotheliumrelated MBF responses to cold exposure remains un- certain, but it may be related to an improvement in the endothelial oxidation-reduction equilibrium resulting in increased expression of eNOS or prevention of eNOS uncoupling through enhanced bioavailability of BH4. ${ }^{97,100,101}$

\section{INSULIN RESISTANCE AFFECTING CORONARY CIRCULATION}

In recent years, obesity, which is frequently associated with the insulin resistance syndrome and systemic microinflammation, has been recognized as an increasing risk factor for cardiovascular morbidity and death. ${ }^{102}$ The exact mechanisms by which obesity initiates and accelerates coronary vascular disease remain to be investigated. Studying coronary circulatory function with PET demonstrated that insulin-resistant patients without traditional coronary risk factors may present abnormalities in coronary circulatory function. ${ }^{20}$ In these individuals with insulin resistance, the endothelium-related MBF response to CPT was diminished whereas hyperemic MBF during dipyridamole stimulation was still preserved. Consequently, the functional abnormality in this group of insulin-resistant individuals was confined to the coronary vascular endothelium. Notably, whereas initial stages of the vascular injury may only involve the endothelium, ${ }^{17,56,75,103}$ more advanced stages of coronary risk factor states, such as increases in oxidative stress burden, may also lead to an impairment in smooth muscle cell vasodilator function. ${ }^{97}$ For example, functional abnormality of the coronary circulation in individuals with increasing body weight progresses from an impairment in endothelium-dependent MBF response to CPT in the overweight condition to an impairment of the predominantly endothelium-independent hyperemic MBFs during dipyridamole stimulation in the obese condition (Figure $7 A$ and $B$ ) ${ }^{18}$ Similar observations were reported by Prior et al, ${ }^{19}$ who observed a progressive worsening of functional abnormalities of endotheliumdependent vasomotion to manifest with increasing severity of insulin resistance and carbohydrate intolerance, whereas attenuated endothelium-independent hyperemic flow responses to pharmacologic vasodilation paralleled the more clinically evident metabolic abnormalities in diabetes. In support of the latter findings, patients with type 1 and type 2 diabetes mellitus revealed a comparable marked impairment of hyperemic MBFs that was related to euglycemic control and that also correlated inversely with plasma glucose concentrations averaged over several months. ${ }^{60,104-108}$

In a more complex setting the assessment of coronary circulatory function in overweight individuals with PET could demonstrate that increases in body weight, paralleled by an increase in plasma markers of the insulin 

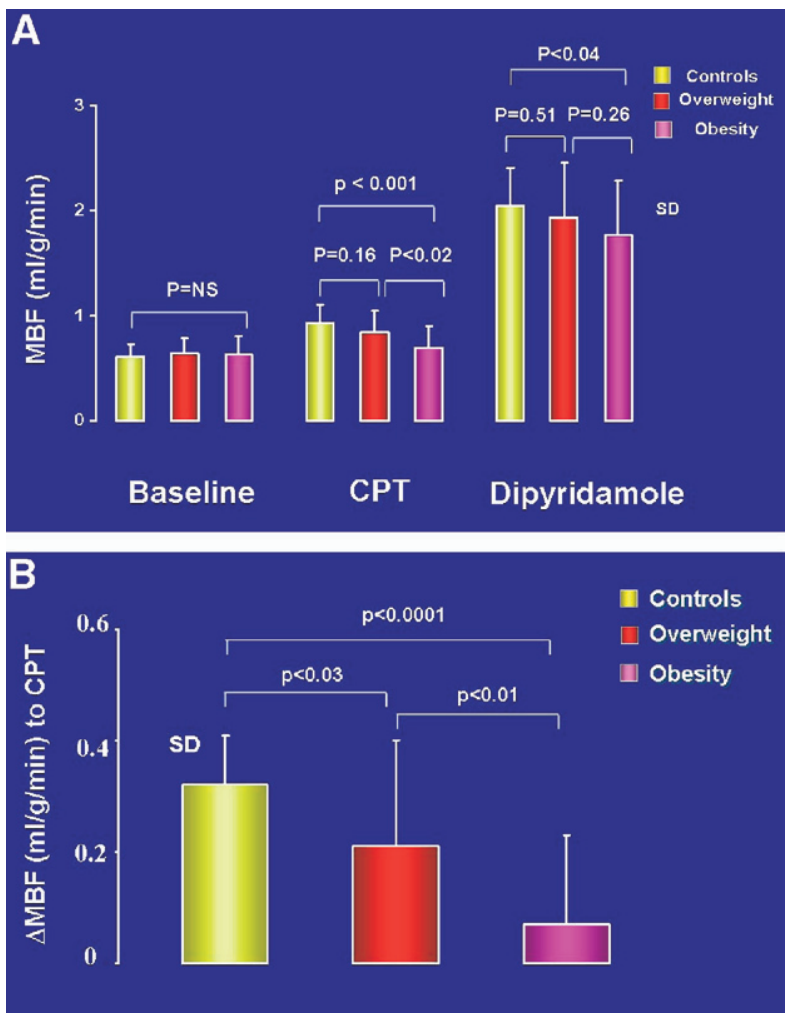

Figure 7. A, MBF at rest, during CPT, and during pharmacologic vasodilation with dipyridamole for the three study groups. The dipyridamole-stimulated MBF was lower in overweight patients than in control subjects, though not significantly. In obese patients the hyperemic MBFs during dipyridamole stimulation were lowest. B, Change in endothelium-related MBF during $\mathrm{CPT}(\triangle \mathrm{MBF})$ for the three study groups. As shown, there was a progressive decrease in the endothelium-related MBF response to CPT from control subjects to overweight patients and obese patients. $N S$, Not significant (Reprinted with permission from reference. ${ }^{18}$ )

resistance syndrome and chronic inflammation, were independently associated with abnormal coronary circulatory function. ${ }^{18}$ These findings provided first evidence showing that obesity is an alternate mediator of coronary vascular disease rather than an epiphenomenon related to other traditional coronary risk factors. ${ }^{18,109}$ Of interest, the role of adipocytokines such as leptin, adiponectin, or ghrelin affecting the coronary circulation in humans is controversial and remains to be investigated. ${ }^{10,111}$ For example, in in vitro studies, leptin released from the adipose tissue may stimulate proatherosclerotic effects, such as increases in ROS in cultured human endothelial cells, acceleration of vascular cell calcification, smooth muscle cell proliferation, and migration. ${ }^{112}$ On the other hand, leptin may induce both endothelium-dependent and -independent vasodilation, ${ }^{113-115}$ indicating NO-mediated antiatherosclerotic effects. ${ }^{116}$ In view of these contrasting observations, PET imaging in obese individ- uals demonstrated a significant and positive association between leptin plasma levels and endothelium-related MBFs to CPT $(r=0.37, P<.036)$. Increases in leptin plasma levels, therefore, were associated with relatively higher endothelium-related MBF increases to CPT. This positive association might be suggestive of a beneficial effect of leptin or leptin-related but still undetermined factors on the coronary endothelium to counteract the adverse effects of increases in body weight on coronary vasomotor function. ${ }^{18}$ As a recent investigation has shown, analyzing PET measurements of MBF and plasma markers of various coronary risk factors may be a unique means by which to tease out the adverse or beneficial effects of various factors on coronary circulatory function in complex in vivo conditions. ${ }^{18}$ Although experimental investigations are most important to investigate a direct cause-effect relationship, ${ }^{84,98,117}$ in vivo imaging with PET may contribute to denote important associations between coronary risk factors and coronary vascular state.

\section{MONITORING RESPONSES TO THERAPEUTIC INTERVENTION}

On the basis of the central role of coronary circulatory dysfunction in the development and progression of atherosclerosis, improvement of abnormal endothelial-dependent coronary vasomotion by a variety of interventions, such as angiotensin-converting enzyme inhibitors, ${ }^{118} \beta$-hydroxymethylglutaryl-coenzyme A reductase inhibitors, ${ }^{78,119}$ hormone replacement therapy in postmenopausal women, ${ }^{75}$ euglycemic control in diabetic patients, and physical exercise, ${ }^{21,120}$ has become a primary therapeutic goal in the prevention of the atherosclerotic process. Notably, Fichtlscherer et al ${ }^{121}$ reported that a normalization of endothelial function of the forearm circulation was paralleled by event-free survival in patients having had an acute coronary syndrome, but not in those who did not show a restoration of forearm vasomotor function as a result of standard therapy. Similar findings were reported by Modena et al ${ }^{122}$ in hypertensive postmenopausal women. An improvement in brachial artery flow-mediated and, thus, endothelium-dependent vasodilation after institution of medical therapy to control arterial hypertension resulted in an improved clinical outcome as compared with those postmenopausal women who did not respond. Though low in numbers, these preliminary results support the evolving concept that improvement in vasomotor function in the peripheral and coronary circulation could indeed mediate an improvement in clinical outcome. If this holds true in future clinical studies, then the assessment of coronary circulatory function by PET imaging could be a promising and unique tool to suc- 
cessfully guide preventive medical therapy in the development or progression of the CAD process.

In this regard, long-term estrogen replacement in postmenopausal women without traditional coronary risk factors may improve endothelium-related MBF responses to CPT, whereas no such effect was observed with short-term administration ${ }^{75,123,124}$ or in postmenopausal women with traditional coronary risk factors. ${ }^{75}$ In addition, $\beta$-hydroxymethylglutaryl-coenzyme A reductase inhibitors (simvastatin) beneficially altered the lipid profile in hypercholesterolemic patients, which was accompanied by a significant increase in dipyridamole-stimulated mean hyperemic MBF from $1.82 \pm 0.36 \mathrm{~mL} \cdot \mathrm{g}^{-1} \cdot \mathrm{min}^{-1}$ at baseline to $2.38 \pm 0.58 \mathrm{~mL} \cdot \mathrm{g}^{-1} \cdot \mathrm{min}^{-1}$ at follow-up, as measured with N-13 ammonia and PET. ${ }^{119}$ Such an improvement in coronary circulatory function in hypercholesterolemic patients after lipid-lowering therapy with $\beta$-hydroxymethylglutaryl-coenzyme A reductase inhibitors was confirmed by other investigations. ${ }^{125-127}$ Interestingly, studying coronary circulatory function with PET demonstrated that insulin-resistant patients without traditional coronary risk factors may present abnormalities in coronary vasomotor function. ${ }^{20}$ More excitingly, insulin-sensitizing thiazolidinedione therapy normalized abnormal MBF responses to CPT in 25 individuals with insulin resistance. The effects of glucose-lowering therapy on coronary circulatory function in type 2 diabetic patients were studied as well. ${ }^{21}$ Three months of glucoselowering treatment with glyburide and metformin significantly improved the coronary endothelium-mediated vasomotor function (Figure $8 A$ ). Of note, the decrease in plasma glucose levels significantly correlated with the improvement in endothelium-related MBF responses to CPT and, thus, an improvement in coronary vasomotor function or dysfunction $(r=0.67, P<.01)$ (Figure $8 B$ ). This association suggests a direct adverse effect of elevated plasma glucose levels, apart from the adverse effects of the insulin resistance syndrome, on diabetesrelated coronary vascular disease in a preclinical state of CAD.

\section{CONCLUSIONS}

Combining cardiac PET perfusion imaging with tracer kinetic models affords the noninvasive assessment of regional MBF in milliliters per gram per minute, which offers important in vivo insight into the complex nature of the mechanisms underlying functional alterations of the coronary circulation. Thus, cardiac PET imaging may contribute to unravel the pathophysiology of the early development of the atherosclerotic process. Such in vivo imaging with PET may denote important associations between coronary risk factors and coronary circulatory function, which may complement or even
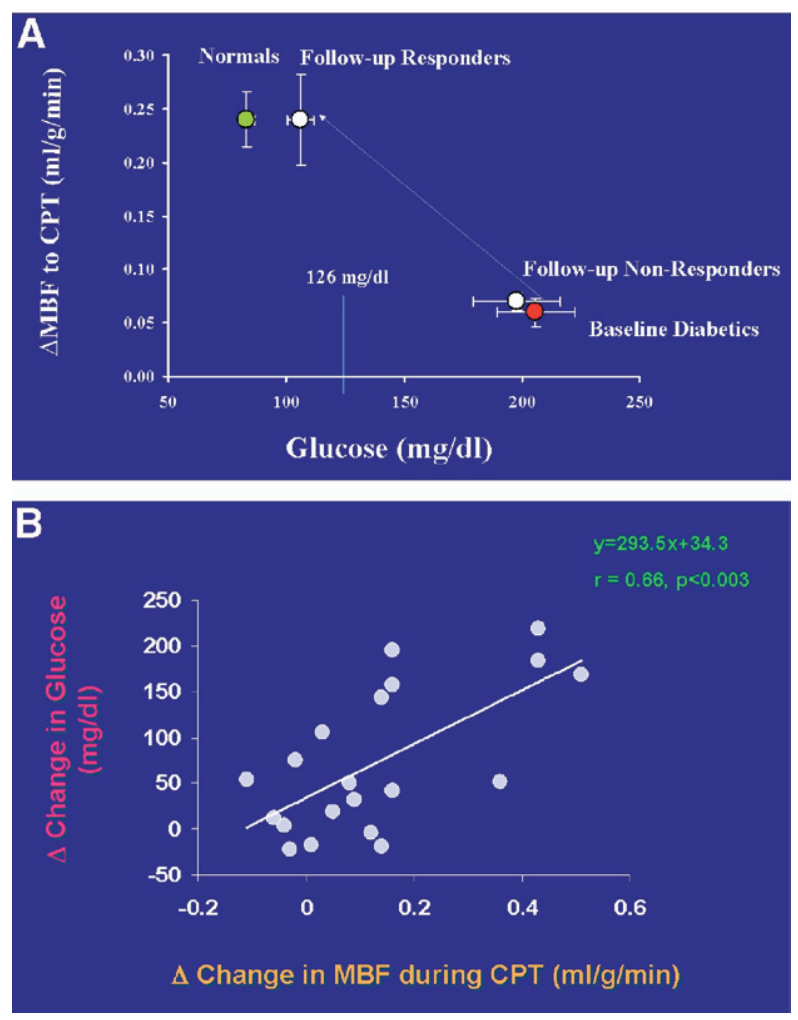

Figure 8. A, Effects of glucose-lowering therapy with glyburide and metformin on endothelium-related $\triangle \mathrm{MBF}$ to CPT in patients with type 2 diabetes mellitus. In type 2 diabetic patients with euglycemic control after 3 months of glucoselowering treatment with glucose plasma levels of $126 \mathrm{mg} / \mathrm{dL}$ or less (responders), the endothelium-mediated MBF response to CPT significantly increased comparable to control subjects, whereas in patients with glucose plasma levels greater than 126 $\mathrm{mg} / \mathrm{dL}$ (nonresponders), virtually no change in $\triangle \mathrm{MBF}$ to $\mathrm{CPT}$ was observed. B, Association of endothelium-related $\triangle \mathrm{MBF}$ to $\mathrm{CPT}$ and change in fasting plasma glucose concentration as defined by difference in measurements between 3 months of follow-up and baseline. (Reprinted with permission from reference. $^{21}$ )

contrast experimental studies that investigate direct cause-effect relationships. Furthermore, by assessing MBFs at rest and during vasomotor stress, the functional consequences of structural or functional alterations in the coronary circulation may be identified before hemodynamically significant obstructive CAD may manifest. The identification of such early structural or functional abnormalities of the coronary circulation appears to carry important diagnostic and prognostic information. Whether an improvement or even restoration of abnormal functional alterations of coronary circulatory function as a result of preventive medical intervention also results in an improved clinical outcome in these patients warrants further investigation. 


\section{Acknowledgment}

The authors have indicated they have no financial conflicts of interest.

\section{References}

1. Kuhle WG, Porenta G, Huang SC, Buxton D, Gambhir SS, Hansen $\mathrm{H}$, et al. Quantification of regional myocardial blood flow using $13 \mathrm{~N}$-ammonia and reoriented dynamic positron emission tomographic imaging. Circulation 1992;86:1004-17.

2. Kaufmann PA, Camici PG. Myocardial blood flow measurement by PET: technical aspects and clinical applications. J Nucl Med 2005;46:75-88.

3. Schelbert HR, Phelps ME, Huang SC, MacDonald NS, Hansen H, Selin C, et al. N-13 ammonia as an indicator of myocardial blood flow. Circulation 1981;63:1259-72.

4. Bergmann SR, Fox KA, Rand AL, McElvany KD, Welch MJ, Markham J, et al. Quantification of regional myocardial blood flow in vivo with H215O. Circulation 1984;70:724-33.

5. Camici PG, Crea F. Coronary microvascular dysfunction. N Engl J Med 2007;356:830-40.

6. Schindler TH, Schelbert HR. Measurements of myocardial blood flow and monitoring therapy. In: Zaret BL, Beller GA. Nuclear cardiology: state of the art and future directions. $3^{\text {rd }}$ ed. Philadelphia: Mosby; 2005. p. 399-412.

7. Ganz P, Vita JA. Testing endothelial vasomotor function: nitric oxide, a multipotent molecule. Circulation 2003;108:2049-53.

8. Widlansky ME, Gokce N, Keaney JF Jr, Vita JA. The clinical implications of endothelial dysfunction. J Am Coll Cardiol 2003;42:1149-60.

9. Schindler TH, Nitzsche EU, Schelbert HR, Olschewski M, Sayre J, Mix M, et al. Positron emission tomography-measured abnormal responses of myocardial blood flow to sympathetic stimulation are associated with the risk of developing cardiovascular events. J Am Coll Cardiol 2005;45:1505-12.

10. Lerman A, Zeiher AM. Endothelial function: cardiac events. Circulation 2005;111:363-8.

11. Schindler TH, Hornig B, Buser PT, Olschewski M, Magosaki N, Pfisterer M, et al. Prognostic value of abnormal vasoreactivity of epicardial coronary arteries to sympathetic stimulation in patients with normal coronary angiograms. Arterioscler Thromb Vasc Biol 2003;23:495-501.

12. Schachinger V, Britten MB, Zeiher AM. Prognostic impact of coronary vasodilator dysfunction on adverse long-term outcome of coronary heart disease. Circulation 2000;101:1899-906.

13. Britten MB, Zeiher AM, Schachinger V. Microvascular dysfunction in angiographically normal or mildly diseased coronary arteries predicts adverse cardiovascular long-term outcome. Coron Art Dis 2004;15:259-64.

14. Cecchi F, Olivotto I, Gistri R, Lorenzoni R, Chiriatti G, Camici PG. Coronary microvascular dysfunction and prognosis in hypertrophic cardiomyopathy. N Engl J Med 2003;349:1027-35.

15. Schindler TH, Nitzsche EU, Munzel T, Olschewski M, Brink I, Jeserich $\mathrm{M}$, et al. Coronary vasoregulation in patients with various risk factors in response to cold pressor testing: contrasting myocardial blood flow responses to short- and long-term vitamin C administration. J Am Coll Cardiol 2003;42:814-22.

16. Hattori N, Schnell O, Bengel FM, Rihl J, Nekolla SG, Drzezga AE, et al. Deferoxamine improves coronary vascular responses to sympathetic stimulation in patients with type 1 diabetes mellitus. Eur J Nucl Med Mol Imaging 2002;29:891-8.

17. Schindler TH, Nitzsche EU, Olschewski M, Magosaki N, Mix M, Prior JO, et al. Chronic inflammation and impaired coronary vasoreactivity in patients with coronary risk factors. Circulation 2004;110:1069-75.

18. Schindler TH, Cardenas J, Prior JO, Facta AD, Kreissl MC, Zhang XL, et al. Relationship between increasing body weight, insulin resistance, inflammation, adipocytokine leptin, and coronary circulatory function. J Am Coll Cardiol 2006;47:1188-95.

19. Prior JO, Quinones MJ, Hernandez-Pampaloni M, Facta AD, Schindler TH, Sayre JW, et al. Coronary circulatory dysfunction in insulin resistance, impaired glucose tolerance, and type 2 diabetes mellitus. Circulation 2005;111:2291-8.

20. Quinones MJ, Hernandez-Pampaloni M, Schelbert H, BulnesEnriquez I, Jimenez X, Hernandez G, et al. Coronary vasomotor abnormalities in insulin-resistant individuals. Ann Intern Med 2004;140:700-8.

21. Schindler TH, Facta AD, Prior JO, Cadenas J, Hsueh WA, Quinones MJ, et al. Improvement in coronary vascular dysfunction produced with euglycaemic control in patients with type 2 diabetes. Heart 2007;93:345-9.

22. Cohn JN, Quyyumi AA, Hollenberg NK, Jamerson KA. Surrogate markers for cardiovascular disease: functional markers. Circulation 2004;109(Suppl 1):IV31-46.

23. Drexler H. Endothelial dysfunction: clinical implications. Prog Cardiovasc Dis 1997;39:287-324.

24. Ludmer PL, Selwyn AP, Shook TL, Wayne RR, Mudge GH, Alexander RW, et al. Paradoxical vasoconstriction induced by acetylcholine in atherosclerotic coronary arteries. N Engl J Med 1986;315:1046-51.

25. Zeiher AM, Drexler H, Wollschlager H, Just H. Modulation of coronary vasomotor tone in humans. Progressive endothelial dysfunction with different early stages of coronary atherosclerosis. Circulation 1991;83:391-401.

26. Rossen JD, Quillen JE, Lopez AG, Stenberg RG, Talman CL, Winniford MD. Comparison of coronary vasodilation with intravenous dipyridamole and adenosine. J Am Coll Cardiol 1991;18: 485-91.

27. Nitzsche EU, Choi Y, Czernin J, Hoh CK, Huang SC, Schelbert HR. Noninvasive quantification of myocardial blood flow in humans. A direct comparison of the $[13 \mathrm{~N}]$ ammonia and the [15O]water techniques. Circulation 1996;93:2000-6.

28. Mullani NA, Goldstein RA, Gould KL, Marani SK, Fisher DJ, O'Brien HA, et al. Myocardial perfusion with rubidium-82. I. Measurement of extraction fraction and flow with external detectors. J Nucl Med 1983;24:898-906.

29. Di Carli MF, Hachamovitch R. New technology for noninvasive evaluation of coronary artery disease. Circulation 2007;115:1464-80.

30. Sampson UK, Dorbala S, Limaye A, Kwong R, Di Carli MF. Diagnostic accuracy of rubidium-82 myocardial perfusion imaging with hybrid positron emission tomography/computed tomography in the detection of coronary artery disease. J Am Coll Cardiol 2007;49:1052-8.

31. Weinberg IN, Huang SC, Hoffman EJ, Araujo L, Nienaber C, Grover-McKay $\mathrm{M}$, et al. Validation of PET-acquired input functions for cardiac studies. J Nucl Med 1988;29:241-7.

32. Gambhir SS, Schwaiger M, Huang SC, Krivokapich J, Schelbert HR, Nienaber CA, et al. Simple noninvasive quantification method for measuring myocardial glucose utilization in humans employing positron emission tomography and fluorine-18 deoxyglucose. J Nucl Med 1989;30:359-66.

33. Bol A, Melin JA, Vanoverschelde JL, Baudhuin T, Vogelaers D, De Pauw M, et al. Direct comparison of [13N] ammonia and [15O]water estimates of perfusion with quantification of regional myocardial blood flow by microspheres. Circulation 1993;87:512-25.

34. Coffman JD, Gregg DE. Reactive hyperemia characteristics of the myocardium. Am J Physiol 1960;199:1143-9. 
35. Mosher P, Ross J Jr, McFate PA, Shaw RF. Control of coronary blood flow by an autoregulatory mechanism. Circ Res 1964;14:250-9.

36. Czernin J, Muller P, Chan S, Brunken RC, Porenta G, Krivokapich J, et al. Influence of age and hemodynamics on myocardial blood flow and flow reserve. Circulation 1993;88:62-9.

37. Morita K, Tsukamoto T, Naya M, Noriyasu K, Inubushi M, Shiga $\mathrm{T}$, et al. Smoking cessation normalizes coronary endothelial vasomotor response assessed with 15O-water and PET in healthy young smokers. J Nucl Med 2006;47:1914-20.

38. Tsukamoto T, Morita K, Naya M, Katoh C, Inubushi M, Kuge Y, et al. Myocardial flow reserve is influenced by both coronary artery stenosis severity and coronary risk factors in patients with suspected coronary artery disease. Eur J Nucl Med Mol Imaging 2006;33:1150-6.

39. Bergmann SR, Herrero P, Markham J, Weinheimer CJ, Walsh MN. Noninvasive quantitation of myocardial blood flow in human subjects with oxygen-15-labeled water and positron emission tomography. J Am Coll Cardiol 1989;14:639-52.

40. Chareonthaitawee P, Kaufmann PA, Rimoldi O, Camici PG. Heterogeneity of resting and hyperemic myocardial blood flow in healthy humans. Cardiovasc Res 2001;50:151-61.

41. Tamaki N, Yonekura Y, Senda M, Kureshi SA, Saji H, Kodama S, et al. Myocardial positron computed tomography with $13 \mathrm{~N}$-ammonia at rest and during exercise. Eur J Nucl Med 1985;11:246-51.

42. Senneff MJ, Geltman EM, Bergmann SR. Noninvasive delineation of the effects of moderate aging on myocardial perfusion. J Nucl Med 1991;32:2037-42.

43. Prior JO, Schindler TH, Facta AD, Hernandez-Pampaloni M, Campisi R, Dahlbom M, et al. Determinants of myocardial blood flow response to cold pressor testing and pharmacologic vasodilation in healthy humans. Eur J Nucl Med Mol Imaging 2007;34:20-7.

44. Sawada S, Muzik O, Beanlands RS, Wolfe E, Hutchins GD, Schwaiger M. Interobserver and interstudy variability of myocardial blood flow and flow-reserve measurements with nitrogen 13 ammonia-labeled positron emission tomography. J Nucl Cardiol 1995;2:413-22.

45. Krivokapich J, Smith GT, Huang SC, Hoffman EJ, Ratib O, Phelps ME, et al. 13N ammonia myocardial imaging at rest and with exercise in normal volunteers. Quantification of absolute myocardial perfusion with dynamic positron emission tomography. Circulation 1989;80:1328-37.

46. Duvernoy CS, Meyer C, Seifert-Klauss V, Dayanikli F, Matsunari I, Rattenhuber J, et al. Gender differences in myocardial blood flow dynamics: lipid profile and hemodynamic effects. J Am Coll Cardiol 1999;33:463-70.

47. Wyss CA, Koepfli P, Mikolajczyk K, Burger C, von Schulthess GK, Kaufmann PA. Bicycle exercise stress in PET for assessment of coronary flow reserve: repeatability and comparison with adenosine stress. J Nucl Med 2003;44:146-54.

48. Namdar M, Koepfli P, Grathwohl R, Siegrist PT, Klainguti M, Schepis T, et al. Caffeine decreases exercise-induced myocardial flow reserve. J Am Coll Cardiol 2006;47:405-10.

49. Schindler TH, Nitzsche EU, Olschewski M, Brink I, Mix M, Prior $\mathrm{J}$, et al. PET-measured responses of MBF to cold pressor testing correlate with indices of coronary vasomotion on quantitative coronary angiography. J Nucl Med 2004;45:419-28.

50. Jagathesan R, Barnes E, Rosen SD, Foale RA, Camici PG. Comparison of myocardial blood flow and coronary flow reserve during dobutamine and adenosine stress: implications for pharmacologic stress testing in coronary artery disease. J Nucl Cardiol 2006;13:324-32.

51. Hernandez-Pampaloni M, Keng FY, Kudo T, Sayre JS, Schelbert HR. Abnormal longitudinal, base-to-apex myocardial perfusion gradient by quantitative blood flow measurements in patients with coronary risk factors. Circulation 2001;104:527-32.
52. Schindler TH, Facta AD, Prior JO, Campisi R, Inubushi M, Kreissl MC, et al. PET-measured heterogeneity in longitudinal myocardial blood flow in response to sympathetic and pharmacologic stress as a non-invasive probe of epicardial vasomotor dysfunction. Eur J Nucl Med Mol Imaging 2006;33:1140-9.

53. Zeiher AM, Drexler H, Wollschlager H, Just H. Endothelial dysfunction of the coronary microvasculature is associated with coronary blood flow regulation in patients with early atherosclerosis. Circulation 1991;84:1984-92.

54. Nabel EG, Ganz P, Gordon JB, Alexander RW, Selwyn AP. Dilation of normal and constriction of atherosclerotic coronary arteries caused by the cold pressor test. Circulation 1988;77:43-52.

55. Zeiher AM, Drexler H, Saurbier B, Just H. Endothelium-mediated coronary blood flow modulation in humans. Effects of age, atherosclerosis, hypercholesterolemia, and hypertension. J Clin Invest 1993;92:652-62.

56. Campisi R, Czernin J, Schoder H, Sayre JW, Schelbert HR. L-arginine normalizes coronary vasomotion in long-term smokers. Circulation 1999;99:491-7.

57. Sato A, Terata K, Miura H, Toyama K, Loberiza FR Jr, Hatoum $\mathrm{OA}$, et al. Mechanism of vasodilation to adenosine in coronary arterioles from patients with heart disease. Am J Physiol 2005; 288:H1633-40.

58. Zeiher AM, Drexler H, Wollschlaeger H, Saurbier B, Just H. Coronary vasomotion in response to sympathetic stimulation in humans: importance of the functional integrity of the endothelium. J Am Coll Cardiol 1989;14:1181-90.

59. Schwaiger M, Kalff V, Rosenspire K, Haka MS, Molina E, Hutchins GD, et al. Noninvasive evaluation of sympathetic nervous system in human heart by positron emission tomography. Circulation 1990;82:457-64.

60. Di Carli MF, Bianco-Batlles D, Landa ME, Kazmers A, Groehn H, Muzik O, et al. Effects of autonomic neuropathy on coronary blood flow in patients with diabetes mellitus. Circulation 1999;100:813-9.

61. Di Carli MF, Tobes MC, Mangner T, Levine AB, Muzik O, Chakroborty $\mathrm{P}$, et al. Effects of cardiac sympathetic innervation on coronary blood flow. N Engl J Med 1997;336:1208-15.

62. Stevens MJ, Raffel DM, Allman KC, Dayanikli F, Ficaro E, Sandford T, et al. Cardiac sympathetic dysinnervation in diabetes: implications for enhanced cardiovascular risk. Circulation 1998;98: 961-8.

63. Pop-Busui R, Kirkwood I, Schmid H, Marinescu V, Schroeder J, Larkin D, et al. Sympathetic dysfunction in type 1 diabetes: association with impaired myocardial blood flow reserve and diastolic dysfunction. J Am Coll Cardiol 2004;44:2368-74.

64. Kaufmann PA, Gnecchi-Ruscone T, Yap JT, Rimoldi O, Camici PG. Assessment of the reproducibility of baseline and hyperemic myocardial blood flow measurements with 15O-labeled water and PET. J Nucl Med 1999;40:1848-56.

65. Go V, Bhatt MR, Hendel RC. The diagnostic and prognostic value of ECG-gated SPECT myocardial perfusion imaging. J Nucl Med 2004;45:912-21.

66. Kubo S, Tadamura E, Toyoda H, Mamede M, Yamamuro M, Magata $\mathrm{Y}$, et al. Effect of caffeine intake on myocardial hyperemic flow induced by adenosine triphosphate and dipyridamole. J Nucl Med 2004;45:730-8.

67. Buus NH, Bottcher M, Hermansen F, Sander M, Nielsen TT, Mulvany MJ. Influence of nitric oxide synthase and adrenergic inhibition on adenosine-induced myocardial hyperemia. Circulation 2001;104:2305-10.

68. Tawakol A, Forgione MA, Stuehlinger M, Alpert NM, Cooke JP, Loscalzo J, et al. Homocysteine impairs coronary microvascular dilator function in humans. J Am Coll Cardiol 2002; 40:1051-8. 
69. Gould KL, Nakagawa Y, Nakagawa K, Sdringola S, Hess MJ, Haynie M, et al. Frequency and clinical implications of fluid dynamically significant diffuse coronary artery disease manifest as graded, longitudinal, base-to-apex myocardial perfusion abnormalities by noninvasive positron emission tomography. Circulation 2000;101:1931-9.

70. De Bruyne B, Hersbach F, Pijls NH, Bartunek J, Bech JW, Heyndrickx GR, et al. Abnormal epicardial coronary resistance in patients with diffuse atherosclerosis but "normal" coronary angiography. Circulation 2001;104:2401-6.

71. Lim MJ, Kern MJ. Coronary pathophysiology in the cardiac catheterization laboratory. Curr Probl Cardiol 2006;31:493-550.

72. Kern MJ. Coronary physiology revisited: practical insights from the cardiac catheterization laboratory. Circulation 2000;101: 1344-51.

73. Drexler H, Zeiher AM, Wollschlager H, Meinertz T, Just H, Bonzel T. Flow-dependent coronary artery dilatation in humans. Circulation 1989;80:466-74.

74. Cox DA, Vita JA, Treasure CB, Fish RD, Alexander RW, Ganz $\mathrm{P}$, et al. Atherosclerosis impairs flow-mediated dilation of coronary arteries in humans. Circulation 1989;80:458-65.

75. Campisi R, Nathan L, Pampaloni MH, Schoder H, Sayre JW, Chaudhuri G, et al. Noninvasive assessment of coronary microcirculatory function in postmenopausal women and effects of short-term and long-term estrogen administration. Circulation 2002;105:425-30.

76. Wyss CA, Koepfli P, Namdar M, Siegrist PT, Luscher TF, Camici PG, et al. Tetrahydrobiopterin restores impaired coronary microvascular dysfunction in hypercholesterolaemia. Eur J Nucl Med Mol Imaging 2005;32:84-91.

77. Kaufmann PA, Gnecchi-Ruscone T, di Terlizzi M, Schafers KP, Luscher TF, Camici PG. Coronary heart disease in smokers: vitamin $\mathrm{C}$ restores coronary microcirculatory function. Circulation 2000;102:1233-8.

78. Wielepp P, Baller D, Gleichmann U, Pulawski E, Horstkotte D, Burchert W. Beneficial effects of atorvastatin on myocardial regions with initially low vasodilatory capacity at various stages of coronary artery disease. Eur J Nucl Med Mol Imaging 2005;32:1371-7.

79. Nagamachi S, Czernin J, Kim AS, Sun KT, Bottcher M, Phelps ME, et al. Reproducibility of measurements of regional resting and hyperemic myocardial blood flow assessed with PET. J Nucl Med 1996;37:1626-31.

80. Siegrist PT, Gaemperli O, Koepfli P, Schepis T, Namdar M, Valenta I, et al. Repeatability of cold pressor test-induced flow increase assessed with $\mathrm{H}(2)(15) \mathrm{O}$ and PET. J Nucl Med 2006; 47:1420-6.

81. Schindler TH, Zhang XL, Prior JO, Cadenas J, Dahlbom M, Sayre J, et al. Assessment of intra- and interobserver reproducibility of rest and cold pressor test-stimulated myocardial blood flow with (13)N-ammonia and PET. Eur J Nucl Med Mol Imaging 2007; [E-pub ahead of print].

82. Bland JM, Altman DG. Statistical methods for assessing agreement between two methods of clinical measurement. Lancet 1986;1:307-10.

83. Jagathesan R, Kaufmann PA, Rosen SD, Rimoldi OE, Turkeimer F, Foale R, et al. Assessment of the long-term reproducibility of baseline and dobutamine-induced myocardial blood flow in patients with stable coronary artery disease. J Nucl Med 2005;46: 212-9.

84. Cai H, Harrison DG. Endothelial dysfunction in cardiovascular diseases: the role of oxidant stress. Circ Res 2000;87:840-4.

85. Tomai F, Crea F, Gaspardone A, Versaci F, Ghini AS, Chiariello $\mathrm{L}$, et al. Unstable angina and elevated $\mathrm{C}$-reactive protein levels predict enhanced vasoreactivity of the culprit lesion. Circulation 2001;104:1471-6.

86. Faxon DP, Fuster V, Libby P, Beckman JA, Hiatt WR, Thompson RW, et al. Atherosclerotic Vascular Disease Conference: Writing Group III: pathophysiology. Circulation 2004;109:2617-25.

87. Topol EJ, Yadav JS. Recognition of the importance of embolization in atherosclerotic vascular disease. Circulation 2000;101: 570-80.

88. Bonetti PO, Lerman LO, Lerman A. Endothelial dysfunction: a marker of atherosclerotic risk. Arterioscler Thromb Vasc Biol 2003;23:168-75.

89. Rozanski A, Gransar H, Wong ND, Shaw LJ, Miranda-Peats R, Polk D, et al. Clinical outcomes after both coronary calcium scanning and exercise myocardial perfusion scintigraphy. J Am Coll Cardiol 2007;49:1352-61.

90. Nishimura RA, Lerman A, Chesebro JH, Ilstrup DM, Hodge DO, Higano ST, et al. Epicardial vasomotor responses to acetylcholine are not predicted by coronary atherosclerosis as assessed by intracoronary ultrasound. J Am Coll Cardiol 1995;26:41-9.

91. Schuijf JD, Wijns W, Jukema JW, Decramer I, Atsma DE, de Roos A, et al. A comparative regional analysis of coronary atherosclerosis and calcium score on multislice CT versus myocardial perfusion on SPECT. J Nucl Med 2006;47: 1749-55.

92. Madjid M, Toutouzas K, Stefanadis C, Willerson JT, Casscells SW. Coronary thermography for detection of vulnerable plaques. J Nucl Cardiol 2007;14:244-9.

93. Cury RC, Nieman K, Shapiro MD, Nasir K, Cury RC, Brady TJ. Comprehensive cardiac CT study: evaluation of coronary arteries, left ventricular function, and myocardial perfusion-is it possible? J Nucl Cardiol 2007;14:229-43.

94. Kaufmann PA, Gnecchi-Ruscone T, Schafers KP, Luscher TF, Camici PG. Low density lipoprotein cholesterol and coronary microvascular dysfunction in hypercholesterolemia. J Am Coll Cardiol 2000;36:103-9.

95. Yokoyama I, Ohtake T, Momomura S, Nishikawa J, Sasaki Y, Omata M. Reduced coronary flow reserve in hypercholesterolemic patients without overt coronary stenosis. Circulation 1996;94:3232-8.

96. Pitkanen OP, Nuutila P, Raitakari OT, Porkka K, Iida H, Nuotio I, et al. Coronary flow reserve in young men with familial combined hyperlipidemia. Circulation 1999;99:1678-84.

97. Munzel T, Daiber A, Ullrich V, Mulsch A. Vascular consequences of endothelial nitric oxide synthase uncoupling for the activity and expression of the soluble guanylyl cyclase and the cGMP-dependent protein kinase. Arterioscler Thromb Vasc Biol 2005;25:1551-7.

98. Munzel T, Keaney JF Jr. Are ACE inhibitors a "magic bullet" against oxidative stress? Circulation 2001;104:1571-4.

99. Ohgushi M, Kugiyama K, Fukunaga K, Murohara T, Sugiyama S, Miyamoto E, et al. Protein kinase $\mathrm{C}$ inhibitors prevent impairment of endothelium-dependent relaxation by oxidatively modified LDL. Arterioscler Thromb 1993;13:1525-32.

100. May JM. How does ascorbic acid prevent endothelial dysfunction? Free Radic Biol Med 2000;28:1421-9.

101. Heller R, Unbehaun A, Schellenberg B, Mayer B, WernerFelmayer G, Werner ER. L-ascorbic acid potentiates endothelial nitric oxide synthesis via a chemical stabilization of tetrahydrobiopterin. J Biol Chem 2001;276:40-7.

102. Eckel RH, Daniels SR, Jacobs AK, Robertson RM. America's children: a critical time for prevention. Circulation 2005;111: 1866-8. 
103. Campisi R, Czernin J, Schoder H, Sayre JW, Marengo FD, Phelps $\mathrm{ME}$, et al. Effects of long-term smoking on myocardial blood flow, coronary vasomotion, and vasodilator capacity. Circulation 1998;98:119-25.

104. Yokoyama I, Momomura S, Ohtake T, Yonekura K, Nishikawa J, Sasaki Y, et al. Reduced myocardial flow reserve in non-insulindependent diabetes mellitus. J Am Coll Cardiol 1997;30:1472-7.

105. Pitkanen OP, Nuutila P, Raitakari OT, Ronnemaa T, Koskinen PJ, Iida $\mathrm{H}$, et al. Coronary flow reserve is reduced in young men with IDDM. Diabetes 1998;47:248-54.

106. Di Carli MF, Janisse J, Grunberger G, Ager J. Role of chronic hyperglycemia in the pathogenesis of coronary microvascular dysfunction in diabetes. J Am Coll Cardiol 2003;41:1387-93.

107. Srinivasan M, Herrero P, McGill JB, Bennik J, Heere B, Lesniak $\mathrm{D}$, et al. The effects of plasma insulin and glucose on myocardial blood flow in patients with type 1 diabetes mellitus. J Am Coll Cardiol 2005;46:42-8.

108. Herrero P, Peterson LR, McGill JB, Matthew S, Lesniak D, Dence $\mathrm{C}$, et al. Increased myocardial fatty acid metabolism in patients with type 1 diabetes mellitus. J Am Coll Cardiol 2006;47:598-604.

109. Al Suwaidi J, Higano ST, Holmes DR Jr, Lennon R, Lerman A. Obesity is independently associated with coronary endothelial dysfunction in patients with normal or mildly diseased coronary arteries. J Am Coll Cardiol 2001;37:1523-8.

110. Matsuzawa Y. Therapy insight: adipocytokines in metabolic syndrome and related cardiovascular disease. Nat Clin Pract Cardiovasc Med 2006;3:35-42.

111. Avogaro A, de Kreutzenberg SV. Mechanisms of endothelial dysfunction in obesity. Clin Chim Acta 2005;360:9-26.

112. Bouloumie A, Marumo T, Lafontan M, Busse R. Leptin induces oxidative stress in human endothelial cells. FASEB J 1999;13: 1231-8.

113. Vecchione C, Maffei A, Colella S, Aretini A, Poulet R, Frati G, et al. Leptin effect on endothelial nitric oxide is mediated through Akt-endothelial nitric oxide synthase phosphorylation pathway. Diabetes 2002;51:168-73.

114. Lembo G, Vecchione C, Fratta L, Marino G, Trimarco V, d'Amati G, et al. Leptin induces direct vasodilation through distinct endothelial mechanisms. Diabetes 2000;49:293-7.

115. Matsuda K, Teragawa H, Fukuda Y, Nakagawa K, Higashi Y, Chayama K. Leptin causes nitric-oxide independent coronary artery vasodilation in humans. Hypertens Res 2003;26:147-52.

116. Winters B, Mo Z, Brooks-Asplund E, Kim S, Shoukas A, Li D, et al. Reduction of obesity, as induced by leptin, reverses endothelial dysfunction in obese (Lep(ob)) mice. J Appl Physiol 2000;89:2382-90.
117. Hink U, Li H, Mollnau H, Oelze M, Matheis E, Hartmann M, et al. Mechanisms underlying endothelial dysfunction in diabetes mellitus. Circ Res 2001;88:E14-22.

118. Mancini GB, Henry GC, Macaya C, O’Neill BJ, Pucillo AL, Carere RG, et al. Angiotensin-converting enzyme inhibition with quinapril improves endothelial vasomotor dysfunction in patients with coronary artery disease. The TREND (Trial on Reversing ENdothelial Dysfunction) Study. Circulation 1996;94:258-65.

119. Baller D, Notohamiprodjo G, Gleichmann U, Holzinger J, Weise $\mathrm{R}$, Lehmann J. Improvement in coronary flow reserve determined by positron emission tomography after 6 months of cholesterollowering therapy in patients with early stages of coronary atherosclerosis. Circulation 1999;99:2871-5.

120. Czernin J, Barnard RJ, Sun KT, Krivokapich J, Nitzsche E, Dorsey D, et al. Effect of short-term cardiovascular conditioning and low-fat diet on myocardial blood flow and flow reserve. Circulation 1995;92:197-204.

121. Fichtlscherer S, Breuer S, Zeiher AM. Prognostic value of systemic endothelial dysfunction in patients with acute coronary syndromes: further evidence for the existence of the "vulnerable" patient. Circulation 2004;110:1926-32.

122. Modena MG, Bonetti L, Coppi F, Bursi F, Rossi R. Prognostic role of reversible endothelial dysfunction in hypertensive postmenopausal women. J Am Coll Cardiol 2002;40:505-10.

123. Peterson LR, Eyster D, Davila-Roman VG, Stephens AL, Schechtman KB, Herrero P, et al. Short-term oral estrogen replacement therapy does not augment endothelium-independent myocardial perfusion in postmenopausal women. Am Heart J 2001;142:641-7.

124. Duvernoy CS, Rattenhuber J, Seifert-Klauss V, Bengel F, Meyer C, Schwaiger M. Myocardial blood flow and flow reserve in response to short-term cyclical hormone replacement therapy in postmenopausal women. J Gend Specif Med 2001;4:21-7, 47.

125. Guethlin M, Kasel AM, Coppenrath K, Ziegler S, Delius W, Schwaiger M. Delayed response of myocardial flow reserve to lipid-lowering therapy with fluvastatin. Circulation 1999;99: 475-81.

126. Huggins GS, Pasternak RC, Alpert NM, Fischman AJ, Gewirtz H. Effects of short-term treatment of hyperlipidemia on coronary vasodilator function and myocardial perfusion in regions having substantial impairment of baseline dilator reverse. Circulation 1998;98:1291-6.

127. Janatuinen $T$, Laaksonen R, Vesalainen R, Raitakari O, Lehtimaki $\mathrm{T}$, Nuutila $\mathrm{P}$, et al. Effect of lipid-lowering therapy with pravastatin on myocardial blood flow in young mildly hypercholesterolemic adults. J Cardiovasc Pharmacol 2001;38:561-8. 